\title{
OS EFEITOS DA ALTERAÇÃO DE GÊNERO E AS FORÇAS ARMADAS BRASILEIRAS: NECESSIDADE DE ADEQUAÇẤO AO NÚCLEO AXIOLÓGICA CONSTITUCIONAL*
}

\author{
Los efectos del cambio de género y las Fuerzas Armadas \\ brasileñas: necesidad de adecuación al núcleo axiológico \\ constitucional

\begin{abstract}
The effects of gender change and Brazilian Armed Forces: the need of the forces to fit the constitutional axiological core
\end{abstract}

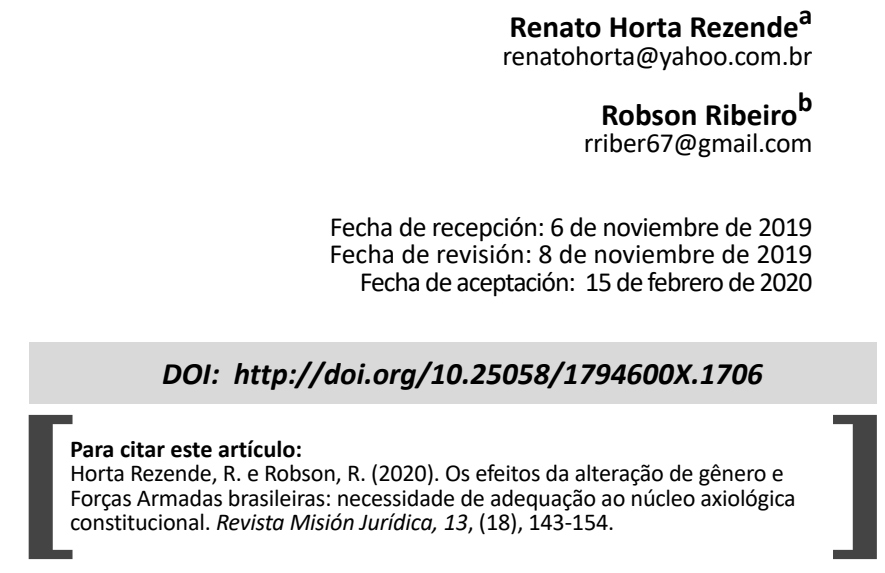

\section{RESUMO}

Com a evolução conceitual e classificatória da transexualidade nas ciências médicas e o desenvolvimento do tema também no Direito, resta observar qual o tratamento jurídico concebido pelas Forças Armadas brasileiras aos militares ou a seus dependentes transgêneros. Diante do problema foi investigada hipótese que considera qualquer afastamento motivado exclusivamente pela transexualidade como inválida a luz dos direitos fundamentais e objetivos da República de 1988, independentemente da época em se der o registro da mudança de gênero em virtude de sua natureza declaratória, fato que também repercute no benefício concedido sobre o critério binário (masculino e feminino) a dependentes. A pesquisa possuiu como referencial teórico a Constituição da República de 1988, tendo sido executada por meio do método hipotético-dedutivo, primordialmente

\footnotetext{
* Artículo de reflexión.

a. Professor de disciplinas afins ao Direito no Centro Universitário UNA (2018 até os dias atuais); Professor do Curso de Direito na Faculdade Pitágoras (2018-2019); Professor do Curso de Direito da FACISA/MG (2018); Diretor da Comissão de Direito das Famílias da OAB-Minas (2019-2021); Mestre em Direito pelo Programa de Pós-graduação em Direito da Universidade Fumec (2016); Especialização em ciência criminais na Faculdade Arnaldo Janssen (2018); graduado em Direito pela Fundação Universidade de Itaúna (2004); Advogado inscrito na Seccional Minas Gerais há treze anos (2005); Professor do CEB-CECON (2007-2011); Professor no CFDs da APMMG (2014); Professor de arbitragem, mediação e conciliação junto ao Conselho Estadual de Arbitragem de Minas Gerais (2009-2018), Árbitro inscrito no CONFEJAB (2015); escritor de livro e vários artigos científicos.

b. Possui graduação em Direito pela Universidade Federal de Uberlândia (2005) e mestrado em Instituições Sociais, Direito e Democracia pela Universidade FUMEC (2017). Atualmente é tabelião - Cartório de Registro Civil e Notas. Tem experiência na área de Direito, com ênfase em Direito Constitucional. Doutorando em Direito Penal pela Universidade Autônoma de Lisboa (2017-2019/2020).
} 
com levantamento bibliográfico, artigos, teses, dissertações, leis e decisões judiciais. A hipótese inicialmente apresentada foi confirmada.

\section{PALAVRAS-CHAVES}

Alteração de gênero; transgênero; Forças Armadas Brasileiras; natureza jurídica; direitos fundamentais; adequação constitucional.

\section{RESUMEN}

Con la evolución conceptual y clasificatoria de la transexualidad en las ciencias médicas y el desarrollo del tema también en el derecho, queda por observar cuál es el tratamiento legal concebido por las Fuerzas Armadas de Brasil a los militares o sus dependientes transgénero. Ante el problema, se investigó una hipótesis que considera inválida cualquier desviación motivada exclusivamente por la transexualidad a la luz de los derechos fundamentales y objetivos de la República de 1988, independientemente del momento en que se registró el cambio de género debido a su naturaleza declaratoria, un hecho que también impactó en el beneficio otorgado en el criterio binario (masculino y femenino) a los dependientes. La investigación tuvo como referencia teórica la Constitución de la República de 1988, que se ejecutó mediante el método hipotético-deductivo, principalmente con encuestas bibliográficas, artículos, tesis, disertaciones, leyes y decisiones judiciales. La hipótesis presentada inicialmente fue confirmada.

\section{PALABRAS CLAVES}

Cambio de género; transgénero; Fuerzas Armadas de Brasil; naturaleza jurídica; derechos fundamentales; adecuación constitucional.

\section{ABSTRACT}

Given the conceptual and classificatory evolution of transsexuality in the medical sciences and the development of the matter also in law, it remains to be observed what the legal treatment conceived by the Brazilian Armed Forces is to the soldiers or their transgender dependents. Faced with the problem, a hypothesis was investigated that considers any suspension motivated exclusively by transsexuality as invalid under the fundamental and objective rights of the 1988 Republican Constitution, regardless of the time when the change of gender was registered due to its declaratory nature. This also impacts the benefit granted on the binary criterion (male and female) to dependents. The research had its as theoretical reference the 1988 Constitution of the Republic, having been executed through the hypotheticaldeductive method, primarily with bibliographic surveys, articles, theses, dissertations, laws and court decisions. The hypothesis initially presented has been confirmed.

\section{KEY WORDS}

Effects; transgender; Brazilian Armed Forces; legal nature; Fundamental Rights.

\section{INTRODUÇÃO}

A evolução do conceito e classificação do transexualismo junto a ciências médicas e no ordenamento jurídico pátrio e internacional, somando aos fundamentos e objetivos da República do Brasil de 1988 enumerados em sua Constituição, criaram novas perspectivas sob o tema e afloram questões até então ignoradas pelas maiorias.

0 julgamento da Ação Direta de Inconstitucionalidade (ADI) no 4.275, proferido pelo Supremo Tribunal Federal (STF) em 01 de março de 2018, seguido do Provimento no 73, de 28 de julho de 2018, autorizou os Cartórios de Registro Civil das Pessoas Naturais a alterarem, mediante auto-declaração, o nome e gênero do interessado, independente de laudo ou procedimento cirúrgico prévio, desjudicializando e inserindo a questão no âmbito da autonomia privada, tornado o procedimento mais simples e célere.

A alteração do gênero no assento civil das pessoas naturais possui amplos reflexos e a evolução acima mencionada não representa o fim das dificuldades impostas, principalmente em corporações tradicionalmente dirigidas ao gênero masculino, sendo importante investigar qual o tratamento jurídico concebido pelas Forças Armadas brasileiras aos militares ou a seus dependentes transgêneros.

Diante do problema foi investigada hipótese que considera qualquer afastamento motivado exclusivamente pela transexualidade como inválida a luz dos direitos fundamentais e objetivos da República de 1988, independentemente da 
época em se der o registro da mudança de gênero em virtude de sua natureza declaratória, fato que também repercute no benefício concedido sobre o critério binário (masculino e feminino) a dependentes.

O desenvolvimento teórico e investigativo impresso na pesquisa compreendem o método científico hipotético-dedutivo em que foram colhidas premissas amplas por meio de levantamento bibliográfico, artigos, tese e dissertações, investigações sobre conclusões de casos específicos e jurisprudências, para se alcançar respostas específicas, sempre possuindo como referencial teórico a Constituição da República de 1988.

A investigação foi construída em três partes, na primeira foi apresentada definições acerca da evolução do conceito e classificação da identidade de genro e a pessoa transgênras; enquanto a parte seguinte restou dedicada a análise da ADI no 4275 e o Provimento no 73 do CNJ e, posteriormente, foram examinadas as adequações necessárias a que as Forças Armadas brasileiras devem colimar esforços com o objetivo de dar eficácia a direito fundamental e objetivo da República.

\section{A IDENTIDADE DE GÊNERO E AS PESSOAS TRANSGÊNERAS}

Gabriel Saad Travassos (2018, p. 72) arrimado na Opinião Consultiva no 24 de novembro de 2017 da disponibilizada pela Corte Interamericana de Direitos Humanos (CIDH) compreende que a identidade de gênero possui conceituação ampla "que cria espaço para a autoidentificação, e que faz referência à vivência que uma pessoa tem de seu próprio gênero. Assim, ela possui uma multiplicidade de formas (...)".

Maíra Coraci Diniz (2014) evidencia que o gênero não é definido por elementos genéticos, sendo construído pelo meio social, por comportamentos e papéis sociais, cabendo à natureza apenas a definição do sexo.

Mariana Tamara de Lima Oliveira (2018) na mesma esteira dos autores acima citados, adverte que a identidade de gênero não é inata ao indivíduo, ou seja, o reconhecimento como homem ou mulher não é naturalmente decorrente da anatomia e tampouco é estabelecida de modo binário, vindo a afirmar que o gênero é construído com o tempo e sob a influência de fatores variados como, genitália, sociedade, convivência familiar, capacidade cognitiva e fatores culturais, sendo assim resultado de vários fatores, tanto naturais, como sociopsicológicos.

Sob esta última perspectiva é possível definir a identidade de gênero como resultante da confluência de fatores corresponde ao estado psicológico reconhecido pelo indivíduo como seu, independente da realidade anatômica binária, se tratando, pois de uma realidade construída de forma abstrata e individual.

Tangenciando a definição de identidade de gênero proposta, ainda que não exista consenso sobre o termo transgênero, este pode ser conceituado como pessoa que compreende estar em desconformidade entre o sexo anatômico e o gênero por ela percebido, tomado aqui como identidade de gênero (Reinaudo y Bacellar, 2008: 22).

A desconformidade gera na maior parte das pessoas transgêneras grandes conflitos psicológico interno, pois acreditam possuir o sexo anatômico em desacordo com a identidade de gênero auto percebida, como bem leciona Jaqueline Gomes Jesus:

Transgêneras: É a expressão "guarda-chuva" utilizada para designar as pessoas que possuem uma identidade de gênero diferente daquela correspondente ao sexo biológico. Há transgêneros heterossexuais, bissexuais e homossexuais. Neste último caso, a orientação sexual da pessoa transgênera é dirigida para alguém com a mesma identidade de gênero, mas de sexo biológico diferente (2012: s/p)

O conceito acima colacionado é resultante de paulatina evolução nos estudos e classificações sobre a pessoa transexual, que, segundo Tereza Rodrigues Vieira (2008), foi dividida em quatro fases: monomania, nosografia, síndrome e atualmente a disforia de gênero.

A primeira fase dos estudos concebia o transexualimo como resultado de psicose limitada ou delírio, algo próximo a loucura, compreendo-o como uma confusão mental da realidade, enquanto na segunda fase a pessoa transexual passa a ser reconhecida como portadora de anomalia dirigida ao comportamento sexual, à perversão sexual e doente. 
Na terceira fase, a transexualidade é apontada como síndrome, afastando-se a classificação relativa à psicose ou perversão das fases anteriores, sendo compreendida como conjunto de sinais e sintomas observáveis em vários processos patológicos diferentes e sem causa específica, independente do homossexualismo ou do travestismo, mas, ainda assim, vista como doença.

$\mathrm{Na}$ quarta e atual fase, inicialmente foi reconhecida a diferença entre sexo e gênero, enquanto o primeiro designa sexualidade, o segundo relaciona-se com a função do sexo no meio social, vindo em decorrência a ser a transexualidade concebida como a perturbação apresenta entre a identidade de gênero e o sexo anatômico, não sendo mais reconhecida como transtorno mental, mas como incongruência de gênero relacionada à sexualidade.

Atento à quarta fase da evolução do conceito e classificação da transexualidade, o Conselho Federal de Psicologia brasileiro (CFP) editou, em 29 de janeiro de 2018, a resolução no 1 que estabelece normas de atuação para os psicólogos em relação às pessoas transexuais $\mathrm{e}$ travestis fundada na: inexistência de patologia a ser tratada, na necessidade de enfrentamento da transfobia e no caráter autodeclaratório da identidade de gênero, objetivando impedir o uso de instrumentos ou técnicas psicológicas para criar, manter ou reforçar preconceitos, estigmas, estereótipos ou discriminação sobre essa parcela da população (CRP, 2018).

Os apontamentos apresentados acerca da quarta fase evolutiva que inspirou a edição da mencionada resolução do CFP, também foi reconhecida pela Organização Mundial da Saúde (OMS), na 11 a revisão da classificação internacional de doença (CID-11) promovida em 18 de junho de 2018, em que foi afastada a classificação de doença mental atribuída ao transexual e reclassificado o transexualismo como condições relacionadas à saúde sexual, realocada da CID-10 F64 para a CID-11 HA-60, que entrará em 2022:

A incongruência de gênero na adolescência e na idade adulta é caracterizada por uma incongruência acentuada e persistente entre o gênero experiente de um indivíduo e o sexo designado, o que muitas vezes leva a um desejo de 'transição', a fim de viver e ser aceito como pessoa do experiente sexo, por meio de tratamento hormonal, cirurgia ou outros serviços de saúde, para alinhar o corpo do indivíduo, tanto quanto desejado e na medida do possível, com o sexo experiente. 0 diagnóstico não pode ser atribuído antes do início da puberdade. 0 comportamento e as preferências das variantes de gênero, por si só, não são uma base para atribuir o diagnóstico (OMS, 2018).

A perturbação decorrente da incongruência entre o sexo e gênero não surge ou manifesta-se repentinamente, mas ocorre de forma cotidiana e paulatina não sendo possível estabelecer com precisão o momento em que o dilema psicológico se instaura e exsurge o desejo de adequação, ainda que para Sigmund Freud (1856-1939) a identidade de gênero venha a ser definida na vida não adulta (Feist, Feits y Roberts, 2015), já que, principalmente na tenra idade, os fatores sociais estimulantes do conflito não mais intensos.

0 conflito entre a orientação sexual não harmonizada com o sexo anatômico resultante da discordância entre a identidade de gênero e a genitália é agravada pela repercussão e prevalência jurídica do sexo legal, aquele constante em documentos oficiais, que possui como único critério definidor as características anatômicas binária do órgão sexual (OLIVEIRA, 2018) e desconsidera, por conseguinte, a capacidade da pessoa se auto-definir.

Diante da repercussão geral do tema, em respeito ao princípio do direito ao nome, à dignidade da pessoa humana, à personalidade, e à isonomia, o Supremo Tribunal Federal (STF) flexionou a maneira pela qual as pessoas autodeclaradas transgêneras podem solicitar a retificação de seus nomes e gêneros em julgamento proferido na ADI 4.275 (STF, 2018).

Depois da publicação do resultado do julgamento realizado no STF o Conselho Nacional de Justiça (CNJ) publicou o Provimento $73 / 2019$ com a finalidade de instrumentalizar a mencionada decisão proferida que facilitou a conversão do gênero existente no registro civil de pessoas naturais.

Os referidos instrumentos jurídicos trouxeram expressivos avanços adequando-se à realidade médica-científica e ao centro axiológico e fundamento da República, qual seja, a dignidade 
da pessoa humana, objetivando a promoção de todos sem qualquer discriminação.

\section{ADI № 4.275, PROVIMENTO № 73 DO CNJ E OS EFEITO DA NATUREZA JURÍDICA DA ALTERAÇÃO DO PRENOME E DO GÊNERO NO ASSENTO CIVIL DAS PESSOAS NATURAIS}

Constitui objetivo fundamental da república de 1988, dentre outros, a promoção do bem de todos, sem preconceito de sexo ou outras formas de discriminação, preceito que inclui, nas palavras de Britto (2003), certamente inspirada na proposta de Dromi (1997), uma nova perspectiva de igualdade, sedimentada na solidariedade dos povos, na dignidade da pessoa humana e na justiça social instituidora do constitucionalismo fraterno.

Por sua vez, o constitucionalismo fraterno homenageia o pluralismo como valor sociopolíticocultural e tem como pretensão a promoção da integração comunitária das pessoas por meio de uma igualdade civil-moral dos estratos sociais que histórica e dolosamente foram ignorados ou segregados em virtude de uma homogeneidade ficta e marginalizante (Britto, 2003).

Diniz (2014) argumenta sobe os efeitos da homogeneidade que impõe a observação do sistema binário masculino ou feminino não são capazes de agasalhar todos os comportamentos sociais e em função disto produz estereótipos que reforçam um discurso de exclusão e discriminação social dos cidadãos que não se enquadram no padrão estabelecido como decorrente da anatomia, fato que atenta contra os fundamentos e objetivos da República de 1988.

Fundado no constitucionalismo fraterno, assim como em atenção ao princípio constitucional da isonomia material, da livre expressão da autonomia da vontade e da dignidade da pessoa humana, o STF, na Ação Direta de Inconstitucionalidade (ADI) no 4275, autorizou os Cartórios do Registro Civil das Pessoas Naturais a alterarem administrativamente o prenome e o gênero das pessoas autodeclaradas transgêneras, conferindo assim ao art. 58 da Lei no 6.015, de 31 de dezembro de 1973, interpretação conforme a Constituição da República de 1988, estabelecendo condições que facilitaram, popularizaram e ampliaram os pedidos neste sentido.
A decisão proferida pelo excelso STF confirmar a dignidade da pessoa humana como núcleo do ordenamento jurídico brasileiro, além de também estar aliada ao Pacto de São José da Costa Rica (Decreto 678, de 06 de novembro de 1992) que dispõe acerca do direito ao nome, ao reconhecimento da personalidade jurídica, à liberdade pessoal, à honra e à dignidade, sem perder de vista também a Opinião Consultiva no 24 expedida pela CIDH, que estabelece a identidade de gênero como núcleo componente da dignidade da pessoa humana.

A ampliação das possibilidades de alteração de nome e a possibilidade de mudança de gênero promovida pela interpretação dada pelo STF, retiraram do Judiciário o monopólio sobre a definição do indivíduo sobre a sua própria identidade de gênero sendo assim substancial, pois, desjudicializou a questão, até então reservada ao Judiciário, trazendo ainda o mérito para o seio da autonomia privada.

Com o intuito de normatizar a interpretação constitucional apresentada pelo STF na referida ADI, foi publicado em 29 de junho de 2018, o provimento no 73 do CNJ que disciplinou acerca da averbação da alteração do prenome e do gênero nos assentos de nascimento e casamento de pessoa transgênero no Registro Civil das Pessoas Naturais (RCPN), sem a necessidade de apresentação de laudo psicológico ou comprovação de cirurgia de transgenitalização, em respeito à autonomia privada, confirmando que o desejo de transformação não exige a comprovação (laudo) ou ato (cirurgia), até mesmo porque, surge com o tempo sem poder ser apurado precisamente quando.

Todavia, ainda que o tema tenha sido bem disciplinado e possua fundamentos suficientes para sua aplicação, os efeitos decorrentes do reconhecimento da transexualidade ainda geram inúmeros questionamentos, muitos dos quais se relacionam com a natureza jurídica.

Duas hipóteses são levantadas quanto à natureza do reconhecimento jurídico da transexualidade, a primeira atribui à averbação da sentença ou autodeclaração no RCPN natureza constitutiva, operando-se assim efeito ex nunc; todavia, há aqueles que compreendem que a natureza jurídica do ato é declaratória, o que redundaria em efeitos retroativos e prospectivos possuindo como condicionante, em todo caso, também a averbação da sentença ou autodeclaração no RCPN, incorrendo em efeito $e x$ tunc. 
Em ambas as hipóteses têm-se que a simples exteriorização da posse de estado, ou seja, a exteriorização (publicidade) contínua (permanência) e definitiva da condição trans, por si só, não teria eficácia erga omnes sendo indispensável a averbação da sentença ou autodeclaração no RCPN.

Freitas e Vita (2017), fundado no princípio da segurança jurídica, compreendem que a necessária averbação junto ao RCPN possui natureza jurídica constitutiva e efeito ex nunc para não prejudicar os atos jurídicos formados e concluídos antes de constituída a modificação no assento civil, sendo explícito o fundamento consequencialista.

Camila de Jesus Mello Gonçalves (2012), também adepta ao resultado, reconhece a divergência e pouco aprofundamento sobre o tema em solo brasileiro, vindo a informar que nações estrangeiras como a Itália, Inglaterra, Espanha, Bélgica e Portugal reconhecem que tanto do gênero natural como a transexualidade dependerá da época em que for efetuada a inscrição do registro do fato, possuindo natureza jurídica constitutiva e efeito ex nunc.

Todavia, no Brasil não existe disposição legal que explicite a natureza do reconhecimento jurídico da identidade gênero desassociado da anatomia do nascido. Ademais, como acima mencionado, o gênero é construído com o tempo e sob a influência de fatores variados (Oliveira, 2018) não existindo um momento temporal exato para a sua definição e o desejo transexual de mudança, razão pela qual, a auto-declaração de que trata o Provimento $\mathrm{n}$ o 73 do $\mathrm{CNJ}$ ou a sentença judicial declaratória, com fundamento na posse do estado já incorporada à personalidade, que reconhece a identidade de gênero diferente daquela expressada biologicamente, possui, salvo melhor juízo, natureza jurídica declaratória, ou seja, reconhece algo que de fato já existe no mundo da vida e passa, portanto, a ser reconhecida também no âmbito jurídico.

0 reconhecimento jurídico sobre algo já existente que altera elemento de identificação formal no registro civil adequando-o à realidade não pode ignorar a anterior inadequação para então gerar efeitos apenas subsequentes ao registro civil, justamente por possuir existência prévia ao ato formal meramente declaratório sobre o qual deve-se impor efeito ex tunc.

A definição da natureza e os efeitos jurídicos possuem repercussão relevante no mundo jurídico, tanto nas relações privadas atinentes ao casamento, por exemplo, como também nas relações públicas relativas à seguridade social, Lei Maria da Penha, feminicídio, execução penal e forças armadas.

A evolução conceitual, classificatória e jurídica sobre o transexual não representa o fim das dificuldades impostas às pessoas transgêneras, pois a questão é complexa e muitas vezes atrelada ao preconceito que tem como alvo as minorias (Moura y Lopes, 2014), fato que agravados pelos conflitos internos, falta de informação, preconceito social, ou pela morosidade judicial, faz com que inúmeras pessoas ingressam nos quadros da Administração Pública ou no mercado de trabalho antes de iniciar o processo de transformação física e/ou alteração de nome e gênero em seus documentos de identificação.

Assim, os transgêneros podem vir a iniciar suas respectivas vidas profissionais com o gênero diverso do que possuem atualmente em seus documentos, fato que além do constrangimento inerente a situação, pode resultar em dificuldades ou até mesmo impedimento de exercer atividades ou gozar de direitos assegurados, como veremos nos casos dos militares das forças armadas brasileira e seus dependentes.

\section{A NECESSIDADE DE ADEQUAÇÃO DAS FORÇAS ARMADAS AOS PRINCÍPIOS CONSTITUCIONAIS E A CONDIÇÃO DO TRANGÊNERO}

As normas constitucionais situam-se em um conjunto maior e modular que traçam linhas gerais que devem repercutir em todo o restante do direito, possuindo assim posição privilegiada, efetivada por meio da jurisdição constitucional, exigido do interprete das normas infraconstitucionais e atos os operadores um sentido de adequação, somente se justificando ações e interpretações à luz da Constituição (Fernandes, 2018).

A ausência da referida adequação acima dardejada macula o ato, o tornado inválido e contrário a ordem constitucional, lógica esta que estrutura o atual constitucionalismo que sustenta o ordenamento jurídico brasileiro (Rezende, 2017), portanto, algo relacionado a sua sustentabilidade e credibilidade.

A adequação exigida deve-se operar nos atos praticados por particulares e também por 
toda a Administração (Fernandes, 2018), pois não assentado apenas em fundamentos éticofilosóficos, mas também exigindo eficácia (Sarlet, 2018), não se admitindo o tratamento contrário à dignidade da pessoa humana, à personalidade ou à isonomia, sob pena de invalidade, sendo importante examinar práticas promovidas pelas Forças Armadas brasileiras frente à situação dos transgêneros e a luz do ordenamento jurídico vigente.

\subsection{Reforma compulsória}

O Inquérito Civil n. - 1.30.001.000522/201411 conduzido pelo Ministério Público Federal (MPF) apurou situações em que pessoas foram sistemática e compulsoriamente reformadas sob o fundamento da incapacidade para o serviço ativo militar por sua condição ou opção sexual (MPF, 2017).

Em todos os quatro casos investigados pelo MPF pessoas foram excluídas do serviço ativo das Forças Armadas brasileiras após confirmarem a intenção de realizar transição de gênero, mesmo tendo manifestado inequívoco desejo de permanecer nas fileiras militares, estarem aptas para o exercício de atividades e possuírem qualificação suficiente.

Como fundamento a decisão que conduziu os militares a inatividade, as Forças Armadas brasileiras apresentaram parecer biomédico cujo diagnóstico era o transexualismo, CID$10 \mathrm{~F} 64$, asseverando este como justificativa ao afastamento do militar de suas atividades somada à ausência de posto adequado para lotação feminina, ainda que, no mesmo parecer existisse confirmação do exercício regular e qualificação suficiente para realização de atividades militares.

Ainda que as Forças Armadas brasileiras adotem perspectivas médicas, amparada na CID-10, ainda em vigor no Brasil, sobre a transexualidade, tem-se que além de inadequada frente à quarta fase da evolução sobre o tema, também contraria frontalmente 0 princípio constitucional da dignidade da pessoa humana, epicentro axiológico de todo o ordenamento jurídico pátrio, assim como também contrário aos ditames do Pacto de São José da Costa Rica que proíbe a marginalização baseada na orientação sexual ou de qualquer outra natureza discriminatória, inclusive identidade de gênero.
A justificativa relativa à inexistência de posto de trabalho para o militar transgênero, ou seja, de gênero feminino, afronta a isonomia constitucional, assim como o art. 70 da Lei $\mathrm{n}^{\mathrm{o}}$ 12.705 , de 08 de agosto de 2012, que trata acerca dos requisitos para ingresso nos cursos de formação de militares de carreira especificamente do Exército, e determina a viabilização do ingresso da candidata do sexo feminino na linha militar bélica.

Como afirmado em capítulo anterior, a identidade de gênero é construída paulatinamente e influenciada por vários aspectos, quando somente após, poderá ser manifestado o desejo de transposição, portanto as ações praticadas pelo militar no exercício da função quando ainda não exteriorizada a sua transexualidade, mas já interiorizada, não foi alterada após a revelação da identificação do gênero, justamente porque, não é o fato de se revelar ou promover a alteração no assento civil do nome e/ou do gênero que constitui ou institui a percepção do ser.

Assim, o fato do militar se autodeclarar na forma do Provimento no 73 do CNJ ou judicialmente, não tem o condão de alterado a capacidade para o exercício militar que já desempenhava justamente porque não é o referido ato que o tornou transexual, mas apenas declarou a auto-identificação, fato que não justifica substancialmente qualquer afastamento dos serviços militares.

Todavia, a situação apurada pelo MPF no referido Inquérito Civil que apurou a reforma de militares em virtude da transexualidade, também é enfrentada repetidas vezes pelo Judiciário ${ }^{1}$ que de forma pacífica compreende não ser adequada a determinação do afastamento das atividades exclusivamente em virtude da condição da pessoa transgênera.

Ainda assim, reforma ou reserva compulsória são impostas ao militar que revele ser transgênero, fato que levou o MPF a utilizar da competência a que aludem o art. 6으, XX da Lei complementar no 75 de 20 de maio de 1993 , assim como no art. 27, parágrafo único, IV, Lei no 8.625 de 12 de fevereiro de 1993, e art. 15, da

1. Vg: Processo $n^{-}$0210689-57.2017.4.02.5101; processo $n^{\circ}$ 0000511-73.2018.4.02.0000; Processo $n^{\underline{0}}$ 000051173.2018.4.02.0000 todos juntos ao TRF 2 a região. 
Resolução no 23 de 17 de setembro de 2007, do Conselho Nacional do Ministério Público (CNMP) a expedir a recomendação $\mathrm{PRDC} / \mathrm{RJ} / \mathrm{n}$ o 04 , em 21 de novembro de 2017 ao comando do Exército brasileiro, para que exima-se de repetidas ações que contrariam dispositivos constitucionais, convencionais e legais conforme colacionado:

A) que a transexualidade não seja considerada como motivo determinante para a reforma de militares, nem como forma de incapacidade para o exercício da atividade militar;

B) que sejam estabelecidos programas de reabilitação ou transferência de militares transexuais em funções compatíveis em outros Corpos ou Quadros das Forças Armadas, caso exerçam originalmente funções que não podem ser ocupadas por mulheres;

C) que sejam implementados programas de combate à discriminação, voltados à erradicação da homofobia e transfobia, de modo a não excluir das Forças Armadas as pessoas transgênero ou homossexuais (MPF, 2017).

Os casos examinados no Inquérito Civil n.o 1.30.001.000522/2014-11 que justificaram a expedição da recomendação no 04 de 2017 acima, assim como as ações judiciais que tratam do mesmo tema apresentam o quadro fático preocupante e sistemático de desrespeito pelas Forças Armadas brasileiras dos princípios constitucionais, convencionais e regras infraconstitucionais, desconsiderando também a capacidade ativa do exercício das ações militares, fato que demonstram como ainda são necessárias ações afirmativas e repressivas sobre o tema para que não se tornem preceitos meramente teóricos ou promessas vazias.

\subsection{Pensão por morte para filha solteira e capaz de militar e a situação do trangênero}

Os militares das Forças Armadas brasileiras possuem regras diferenciadas com relação a benefícios auferidos na inatividade ou atribuídos aos seus dependentes, regulados pela Lei de pensões, no 3.765 , de 04 de maio de 1960 , pelo Estatuto dos militares, Lei no 6.880, de 09 de dezembro de 1980 e pela Medida Provisória que reestrutura a remuneração dos militares, no 2.215-10, de 31 de agosto de 2001.
0 parágrafo único do art. $3^{3}$ da Lei $\mathrm{n}^{\mathrm{o}}$ $3.765 / 1960$ fixa alíquota de sete e meio por cento do soldo para custeamento das pensões por morte pagas a dependentes, cônjuge; companheiro; ex-cônjuge ou ex-companheiro beneficiário de pensão alimentícia; filhos, enteados, menor sob guarda ou maior tutelado até vinte e um anos de idade ou vinte e quatro anos de idade se universitário, ou por prazo indeterminado enquanto perdurar incapacidade.

A Medida Provisória 2215-10/2001, ainda em vigor por determinação do art. $2^{\circ}$ da Emenda Constitucional no 32, de 11 de setembro de 2001, extinguiu a instituição de novas pensões por morte por prazo vitalício a serem pagas para filhas dos militares que ingressaram na carreira militar após a publicação da referida medida provisória.

No entanto, a mencionada medida provisória manteve o benefício da pensão por morte já concedida às filhas solteiras de qualquer idade face ao ato jurídico perfeito e concedeu a faculdade aos militares que ingressaram nas Forças Armadas antes da publicação da medida a manter o potencial benefício às suas dependentes mediante a contraprestação doravante equivalente a um e meio por cento do soldo.

A manutenção do referido benefício ou a potencial concessão às beneficiárias, filhas de militares que iniciaram sua carreira antes da mencionada medida provisória está submetido ao modelo binário que trata de forma diferente homens e mulheres, isto porque, ao dependente filho-homem na mesma situação que a dependente filha-mulher, ou seja, capaz e solteiro não é ou será concedido pensão por morte vitalícia.

Estando atrelado ao modelo binário (gênero masculino ou feminino) novamente a questão do transgênero se apresenta como situação que exige maior e melhor reflexão garantindo-se a efetiva aplicação dos direitos e garantias constitucionais.

Primeiramente há que se destacar, conforme anotado acima, que o modelo binário mencionado possui como critério o gênero, masculino ou feminino, cuja sua identidade é definida não pela anatomia, mas por fatores variados (Oliveira, 2018), sendo, portanto possível haver diferença entre a identidade de gênero percebida e a verificada biologicamente (Jesus, 2012), esta última inicialmente definida como sexo legal. 
Todavia, ocorrendo alteração do gênero no registro civil das pessoas naturais, por ato autodeclaratório ou adjudicado, haverá reflexos na concessão ou interrupção da pensão por morte vitalícia a filha de militar.

Novamente a definição da natureza jurídica do ato que reconhece transexualidade e os efeitos decorrentes é de suma importância para identificar o direito a ser aplicado, ou seja, o reconhecimento do ato como constitutivo ou declaratório irá influir na eventual concessão, manutenção ou não do benefício.

Compreendendo que a auto-declaração a que trata o Provimento no $73 / 2018$ do CNJ ou a sentença que reconhece o transgênero possui natureza jurídica declaratória e efeitos ex tunc deve ser observado o reconhecimento do gênero em assento civil na data do requerimento de benefício, podendo ser alterado tanto o gênero como eventual deferimento ou indeferimento do pedido de concessão de benefício.

Assim, pessoa transgênera, anatomicamente identificada como do sexo masculino, caso se reconheça como do sexo contrário e venha a se enquadrar nos demais critérios legais teria direito a perceber o benefício, assim como a alteração em sentido contrário supriria o direito do beneficiário.

Ainda em atenção à natureza jurídica da auto-declaração ou da decisão adjudicada os efeitos devem ser observados também em seu aspecto retroativo, ou seja, mesmo que na época do falecimento do militar, o filho não tenha promovido a retificação no registro civil das pessoas naturais, porém, venha a praticar a alteração em momento posterior, possuindo também os demais requisitos, fará jus à percepção do benefício, condicionada, porém, a percepção das prestações mensais à prescrição quinquenal, conforme determinação contida no art. 71 do Decreto no 49.096, de 10 de outubro de 1960 que regulamenta a Lei no 3.765/1960.

Da mesma forma, a alteração formal da identidade de gênero, feminino para masculino, teria o condão de afastar o direito a percepção de potencial ou mesmo o benefício já instituído.

Compreensão semelhante à acima apresentada foi utilizada em julgado proferido pelo MM juiz
Frederico Montedonio Rego, lotado na 7a Vara da Justiça Federal seção Rio de Janeiro, em 13 de setembro de 2017:

Ao comparecer à Marinha no corrente ano para recadastramento periódico, tendo em vista a continuidade da percepção da pensão ("prova de vida"), o impetrante, hoje com 54 anos de idade, apresentou seus documentos atuais, em que consta seu nome social masculino. Assim, seu benefício foi cancelado, pois entendeu a autoridade impetrada que os dispositivos da Lei no 3.765/1960 "limitam ao filho do sexo masculino o direito à reversão até 21 anos de idade ou até 24 anos de idade, se estudante universitário.

[...]

Portanto, entender que o impetrante seria titular do direito à pensão seria considerá-lo, em alguma medida ou para certos fins, como um indivíduo do sexo feminino, o que reavivaria todo o sofrimento que teve durante a vida e violaria sua dignidade, consubstanciada no seu direito - já reconhecido em juízo - a ser reconhecido tal como é para fins jurídicos, ou seja, como um indivíduo do sexo masculino.

[...]

Assim, agiu com correção a autoridade impetrada ao cancelar a pensão, como também agiria na situação hipotética inversa, se concedesse o benefício a uma requerente identificada com o gênero feminino, apesar de nascida com o sexo masculino. A propósito, não há um problema de direito intertemporal, porque a sentença de fls. 65/68 é meramente declaratória do gênero com o qual o impetrante sempre se identificou desde a infância, tendo apenas legitimado essa situação para fins jurídicos. De toda forma, ainda que se entenda diferentemente, o impetrante deixou de preencher um dos requisitos essenciais para a percepção da pensão, o que autoriza o seu cancelamento. Não é inédita no direito a revisão de benefícios concedidos em razão de uma condição em princípio permanente, mas cuja mudança é incompatível com a continuidade da prestação (e.g., a recuperação da capacidade laborativa implica a cessação de aposentadoria por invalidez). [...]

Embora a presente decisão seja patrimonialmente desvantajosa para o impetrante, ela legitima sua identidade de gênero e sua condição existencial, aspecto mais importante e que deve ser levado a sério em todas as suas consequências (Mandado de Segurança, no 0155101-65.2017.4.02.5101, s/p). 
Verifica-se no fragmento acima que o referido juiz considerou a situação da transexualidade sob a dimensão dos direitos fundamentais assim como os efeitos da sentença declaratória de reconhecimento transexual, compreendendo ser possível a revisão de benefícios concedidos em razão da alteração é incompatível com a continuidade da prestação, mesmo ocorra desvantagem patrimonial.

Na decisão judicial em análise, o magistrado admitiu também que o benefício relativo à pensão por morte de filha solteira de militar teria natureza jurídica previdenciária e não securitária, sendo assim possível a sua reversão.

Ainda que exista divergência sobre a natureza jurídica dos benefícios concedidos aos militares e seus beneficiários, o qual se encontra para além do recorte proposto por este artigo, é importante destacar que a reversão do benefício concedido em virtude da alteração de gênero no assento civil de registro de pessoas naturais tem efeitos apenas prospectivos em virtude de sua condição assistencial e em homenagem à segurança jurídica, não se aplicando o mesmo raciocínio relativo à natureza jurídica do ato que altera o gênero escrito no assento do registro civil das pessoas naturais justamente por serem objetos jurídicos totalmente diferentes.

\section{CONCLUSÃO}

A transexualidade atualmente apresentada constitui resultado de longa evolução tanto social e jurídica como médico-científica não sendo atualmente conceituada nem tampouco classificada como doença.

0 STF na ADI no 4.275, reconhecendo a diferença entre sexo e gênero, assim como aplicando o princípio da isonomia, direito à personalidade e à dignidade da pessoa humana, autorizou os Cartórios do Registro Civil das Pessoas Naturais a alterarem administrativamente o prenome e o gênero das pessoas autodeclaradas transgêneras conferindo assim ao art. 58 da Lei no . 6.015, de 31 de dezembro de 1973, interpretação conforme a Constituição da República de 1988, desjudicializando a questão até então reservadas ao Judiciário.

Diante da necessidade de efetividade do direito fundamental à personalidade, o objetivo de não discriminação e sob o fundamento da República da dignidade da pessoa humana, o $\mathrm{CNJ}$ regulou os efeitos instrumentais da decisão proferida pelo STF por meio do Provimento no 73.

Ainda que exista divergência, a auto-declaração firmada pelo transgênero ou a sentença judicial declaratória possui efeitos ex tunc fato que repercute na esfera jurídica de diversos ramos do Direito e na realidade coorporativa de instituições tradicionais como as Forças Armadas brasileiras.

Ainda que as mudanças normativas venham a facilitar a alteração nos assentos civis de pessoas naturais e inserir pessoas que estavam à margem, de fato, os reflexos do ato podem impor restrições discriminatórias contrárias ao fundamento e aos objetivos da República mesmo dentro da Administração, como ocorre junto às Forças Armadas brasileiras que praticando atos discriminatórios impõem reformas compulsórias aos militares em virtude da transexualidade em afronta a dignidade da pessoa humana, bem como a direitos convencionais e infraconstitucionais.

A reforma compulsória imposta aos transexuais além de afrontar o Direito também se mostra ilógica, pois o desejo de alteração do gênero no registro civil das pessoas naturais com ou sem a submissão a cirurgia de transgenitalização tem como objetivo dar publicidade à identidade de gênero que a pessoa, já integrante das Forças Armadas, possuía não se justificando o afastamento por este motivo quando presente a capacidade e adequação às atividades militares.

A mudança de gênero no assento civil das pessoas naturais também possui reflexo na concessão de pensão por morte à filha de militares solteiras de qualquer idade, isto porque, um dos critérios para concessão de benefício é justamente o binário (masculino ou feminino), devendo ser observado o gênero constante no registro civil da pessoa natural na época do requerimento do benefício independente da alteração pretérita, assim como a sua manutenção enquanto perdurar a condição de dependente.

A questão da pessoa transexual ainda é muito controvertida e necessita aprofundadas reflexões diante de seus reflexos e de critérios assentados no sistema binário de gênero, sendo em todo caso indispensável que qualquer ponderação se 
dê a luz das balizas constitucionais e de seu eixo axiológico como requisito de validade, afastando qualquer compreensão discriminatória ou marginalizante.

\section{BIBLIOGRAFÍA}

- BRASIL. Constituição da República Federativa do Brasil de 05 de outubro de 1988. Disponível em: http://www. planalto.gov.br/ccivil_03/Constituicao/ Constituicao.htm. Acesso em: 23 out. 2019.

- “---.." Decreto no 678, de 06 de novembro de 1992. Disponível em: http://www.planalto. gov.br/ccivil_03/decreto/d0678.htm. Acesso em: 29 out. 2019.

- “---.." Decreto no 49.096, de 10 de outubro de 1960. Disponível em: http://www.planalto. gov.br/ccivil_03/decreto/1950-1969/ D49096.htm. Acesso em: 02 nov. 2019.

- “---.." Emenda Constitucional $n^{-}$32, de 11 de setembro de 2011. Disponível em: http://www.planalto.gov.br/ccivil_03/ constituicao/Emendas/Emc/emc32.htm. Acesso em: 29 out. 2019.

- “---." Lei complementar no 75 de 20 de maio de 1993. Disponível em: http://www. planalto.gov.br/ccivil_03/leis/lcp/lcp75. htm. Acesso em: 29 out. 2019.

- “----." Lei no 3.765, de 4 de maio de 1960. Disponível em: http://www.planalto.gov. br/ccivil_03/Leis/L3765compilado.htm. Acesso em: 29 out. 2019.

- “---.." Lei no 6.880, de 9 de dezembro de 1980. Disponível em: http://www.planalto. gov.br/ccivil_03/LEIS/16880compilada. htm. Acesso em: 29 out. 2019.

- “----." Lei no 8.625 de 12 de fevereiro de 1993. Disponível em: http://www.planalto.gov. br/ccivil_03/Leis/L8625.htm. Acesso em: 29 out. 2019

- “---.." Medida Provisória no 2.215-10, de 31 de agosto de 2001. Disponível em: http://www.planalto.gov.br/ccivil_03/ MPV/2215-10.htm\#art27. Acesso em: 29 out. 2019.
- Britto, C. A. (2003). Teoria da Constituição. São Paulo: Saraiva.

- CIDH. Corte Interamericana de Direitos Humanos. (2017). Opinião Consultiva $n^{\circ}$. 24/2017. Julgado em 24 de novembro de 2017. Disponível em: http://www.corteidh. or.cr/docs/opiniones/seriea_24_esp.pdf . Acesso em: 26 out. 2019.

- CNJ. Provimento no 73, de 28 de junho de 2018. Disponível em: https://atos.cnj.jus. br/atos/detalhar/2623. Acesso em: 03 nov. 2019.

- CNMP. Resolução no 23 de 17 de setembro de 2007. Disponível em: https:// www.cnmp.mp.br/portal/images/ Normas/Resolucoes/Resoluao_23_ alterada_143.1.pdf. Acesso em: 29 out. 2019.

- CRP. Resolução nô1, de 29 de janeiro de 2018. Disponível em: https://site.cfp. org.br/wp-content/uploads/2018/01/ Resolu\%C3\%A7\%C3\%A3o-CFP-01-2018. pdf. Acesso em: 29 out. 2019.

- Diniz, M. C. (2014). Direito a não discriminação: travestilidade $e$ transexualidade. São Paulo: Estúdio Editores.com.

- Dromi, J. R. (1997). La Reforma Constitucional: El Constitucionalismo del "por-venir". En: Enterria, Eduardo Garcia de; ARÉVALO, Manuel Clavero (coord). El Derecho Público de Finales de Siglo: Una Perpectiva Iberoamericana. Madrid: Fundación BBVA, p.107-116.

- Freitas, M. S. de; Vita, J. B. (2017) Distinção de gênero para fins de aposentação e tutela jurídica das pessoas transsexuais. Revista Novos Estudos Jurídicos, Governador Valadares, 22, (1) - 288-323. 
- Fernandes, B. G. (2018). Curso de Direito Constitucional. Salvador: JusPodivm.

- Gonçalves, C. de J. M. (2012). A transexualidade sob a ótica dos direitos humanos: uma perspectiva de inclusão. Tese de Doutorado apresentada perante a Faculdade de Direito da Universidade de São Paulo - USP, ano de 2012, p. 223. Tese integral disponível através do portal: http://www.teses.usp.br/teses/ disponiveis $/ 2 / 2140 /$ tde- 04032013 105438/pt-br.php. Acessado em: 26 out. 2019.

- Jesus, J. G. (2012). Orientações sobre a população transgênero: conceitos e termos. Brasília. Disponível em: https://issuu. com/jaquelinejesus/docs/orienta_-es_ popula_o_trans . Acesso em: 20 jan. 2019.

- Moura, R.G.; Lopes, P.L. (2014). Comportamento organizacional frente à diversidade: a inclusão de travestis e transexuais no mercado de trabalho. En: SIMPÓSIO DE EXCELÊNCIA EM GESTÃO E TECNOLOGIA, XVI, 2014, Rio de Janeiro. Anais [...]. Rio de Janeiro: Faculdades Dom Bosco, p. 01-16.

- MPF. (2017). Inquérito Civil n. 1.30.001.000522/2014-11. Disponível em: http://www.mpf.mp.br/rj/sala-deimprensa/docs/pr-rj/recomendacaotransexuais-forcas-armadas. Acesso em: 03 nov. 2019.

- OMS. (2019). International Classification of Diseases 11th Revision: The global standard for diagnostic health information. Disponível em: https://icd.who.int/ browse11/l-m/en\#/http://id.who.int/icd/ entity/90875286. Acesso em 29 out. 2019.

- Oliveira, M. T. de L. (2018). A aplicabilidade dos direitos fundamentais perante a retificação do registro civil do transexual no Brasil. Dissertação de Mestrado apresentada perante a Universidade Fundação Mineira de Educação e Cultura - FUMEC, ano de 2018, p. 128. Dissertação integral disponível através do portal: http://www.fumec.br/revistas/pdmd/ article/view/673-. Acessado em: 03 nov. 2019.

- Rezende, Renato Horta. (2017). Controle concentrado de constitucionalidade: elemento estrutural de validade das decisões sobre política pública. Curitiba: Jaruá, 2017.

- Reainaudo, Franco y Bacellar, Laura. (2008). O mercado GLS: Como Obter Sucesso Com O Segmento De Maior Potencial Da Atualidade. São Paulo: Matrix.

- Sarlet, I. W. (2018). Art. 1으, III - a dignidade da pessoa humana. En: Canotilho, J.J; Mendes, Gilmar Mendes; Sarlet, Ingo Wolfgang y STRECK, Lênio Luiz (Coord.); Comentários à Constituição do Brasil. São Paulo: Saraiva. p. 294-301.

- STF, Supremo Tribunal Federal. (2018). Ação Direta de Inconstitucionalidade $n^{\circ}$ 4275. Disponível em: http://portal. stf.jus.br/processos/downloadPeca. asp?id=15339649246\&ext=.pdf. Acesso em: 17 out. 2019.

- Travasso, G. S. (2018). A opinião consultiva $n^{\circ}$. 24/2017 da Corte Interamericana de Direitos Humanos: a identidade de gênero como núcleo componente da dignidade da pessoa humana. Revista Defensoria Pública da União, (11), 65-88.

- TRF 2a Região. (2017). Sentença em Mandado de Segurança no 0155101 65.2017.4.02.5101. Disponível em: https://dje.trf2.jus.br/DJE/Paginas/ VisualizaDocumento.aspx?ID=9971580. Acesso em 1 nov. 2019.

- Vieira, T. R. (2008). Nome e Sexo: mudanças no registro civil. São Paulo: Editora Atlas. 